Review

\title{
Molecular Basis of Medullary Thyroid Carcinoma: The Role of RET Polymorphisms
}

\author{
Lucieli Ceolin, Débora R. Siqueira, Mírian Romitti, Carla V. Ferreira and Ana Luiza Maia * \\ Thyroid Section, Endocrine Division, Hospital de Clínicas de Porto Alegre, Universidade Federal do \\ Rio Grande do Sul, Rua Ramiro Barcelos 2350, 90035-003, Porto Alegre, RS, Brazil; \\ E-Mails: lu.ceolin@gmail.com (L.C.); deborarsiqueira@yahoo.com.br (D.R.S.); \\ mirianromitti@bol.com.br (M.R.); carlinhavaz@yahoo.com.br (C.V.F.) \\ * Author to whom correspondence should be addressed; E-Mail: almaia@ufrgs.br; \\ Tel.: +55-51-2101-8127; Fax: +55-51-2101-8777.
}

Received: 10 October 2011; in revised form: 29 November 2011 / Accepted: 20 December 2011 / Published: 27 December 2011

\begin{abstract}
Medullary thyroid carcinoma is a rare malignant tumor originating in parafollicular C cells. It accounts for 5 to $8 \%$ of all thyroid cancers. MTC develops in either sporadic $(75 \%)$ or hereditary form $(25 \%)$. Genetic and molecular studies have demonstrated the involvement of the RET proto-oncogene in hereditary MTC and, less often, in its sporadic form. Although a strong genotype-phenotype correlation has been described, wide clinical heterogeneity is observed among families with the same RET mutation or even in carriers of the same kindred. In recent years, several single nucleotide polymorphisms of the RET gene have been described in the general population as well as in patients with MTC. Some studies have reported associations between the presence of polymorphisms and development or progression of MTC. Nonetheless, other studies failed to demonstrate any effect of the RET variants. Differences in the genetic background of distinct populations or methodological approaches have been suggested as potential reasons for the conflicting results. Here, we review current knowledge concerning the molecular pathogenesis of sporadic and hereditary MTC. In particular, we analyze the role of RET polymorphisms in the clinical presentation and prognosis of MTC based on the current literature.
\end{abstract}

Keywords: medullary thyroid carcinoma; RET polymorphisms; prognosis 


\section{Molecular Basis of Medullary Thyroid Carcinoma}

Medullary thyroid carcinoma (MTC) is a rare malignant tumor originating in parafollicular C cells of the thyroid first described by Hazard et al. [1]. MTC accounts for 5 to $8 \%$ of all thyroid gland tumors and its main secretory product is calcitonin. MTC may occur sporadically, in approximately $75 \%$ of cases, or as part of the inherited cancer syndrome known as multiple endocrine neoplasia type 2 (MEN 2) [2-4]. The reported 10-year mortality rate for patients with MTC varies from 13.5 to 38\% [5-7].

The hereditary form of MTC is associated with germline mutations in the RET (RE arranged during Transfection) proto-oncogene, and presents as an autosomal dominant disease with a high penetrance and variable phenotype. RET point mutations are described mainly in exons 10, 11 and 16. However, less frequent mutations also occur in exons 5, 8, 13, 14 and 15 [8-13]. Hereditary MTC, also referred to as MEN 2, may be classified into three clinically distinct forms: multiple endocrine neoplasia type 2A (MEN 2A), type 2B (MEN 2B) and familial medullary thyroid carcinoma (FMTC) [11,12].

The molecular mechanisms involved in the sporadic MTC have not yet been clarified. About $50-80 \%$ of the cases present a somatic RET mutation M918T (Met/ATG $\rightarrow$ Thr/ACG, exon 16) [14-17]. However, the mutation does not appear to be uniform among the various cell subpopulations in the tumor or in the metastases, suggesting that sporadic MTC might be of polyclonal origin, or that the mutations in the RET proto-oncogene are not initial events in MTC tumorigenesis [14,16].

This review aims at presenting an updated picture of the current knowledge on the molecular pathogenesis of sporadic and hereditary MTC. In particular, we critically analyze the role of RET polymorphisms in the clinical presentation and prognosis of MTC.

\section{The RET Proto-Oncogene}

Genetic and molecular studies have shown the contribution of the RET proto-oncogene in hereditary MTC and, less often, in its sporadic form. The RET gene was identified in 1985 by Takahashi et al. during a classical experiment of NIH 3T3 cell transfection with the high molecular weight DNA of human T-cell lymphoma, hence the naming of the gene as RET (RE arranged during Transfection) [18]. Later, studies determined the RET location in chromosome 10 and related it to the genesis of MEN 2A, MEN 2B and FMTC [19,20]. In 1993, for the first time, point mutations in the RET gene were described in patients with MEN 2A and FMTC [9,13] and in the subsequent year, a specific RET mutation (M918T) was associated with MEN 2B and sporadic MTC [21].

The $R E T$ gene encodes a receptor tyrosine-kinase, expressed in the cells derived from the neural crest: thyroid parathyroid cells (C cells), chromafin cells of the adrenal medulla and enteric autonomic plexus. Since it is a membrane receptor, the RET protein is constituted by three domains: an extracellular domain, a transmembrane domain and an intracellular portion containing two tyrosine-kinase domains (Figure 1). The extracellular domain includes regions homologous to the cadherin family of cell adhesion molecules and a large region rich in cysteine residues that performs the transduction of extracellular signals of proliferation, growth, differentiation, migration, survival and cell apoptosis. The intracellular domain is divided into 2 tyrosine-kinase subdomains (TK1 and TK2), separated by 28 aminoacids. These subdomains contain the tyrosine residues that are phosphorylated during receptor activation, and are involved in the activation of the signaling 
intracellular pathways. $R E T$ is subject to alternative splicing of the $3^{\prime}$ region generating three protein isoforms that contain 9 (RET9), 43 (RET43) and 51 (RET51) amino acids in the carboxy-terminal tail downstream from glycine 1063. RET9 and RET51, consisting of 1072 and 1114 amino acids, respectively, are the main isoforms in vivo [22,23].

Figure 1. Schematic representation of the RET receptor. The extracellular region comprises the cadherin and cysteine rich domain. A single transmembrane region spans the cell membrane. Two tyrosine kinase domains (TK1 and TK2) are located in the intracellular region. The corresponding exons coding for the cysteine and thyrosine kinase domains are indicated.

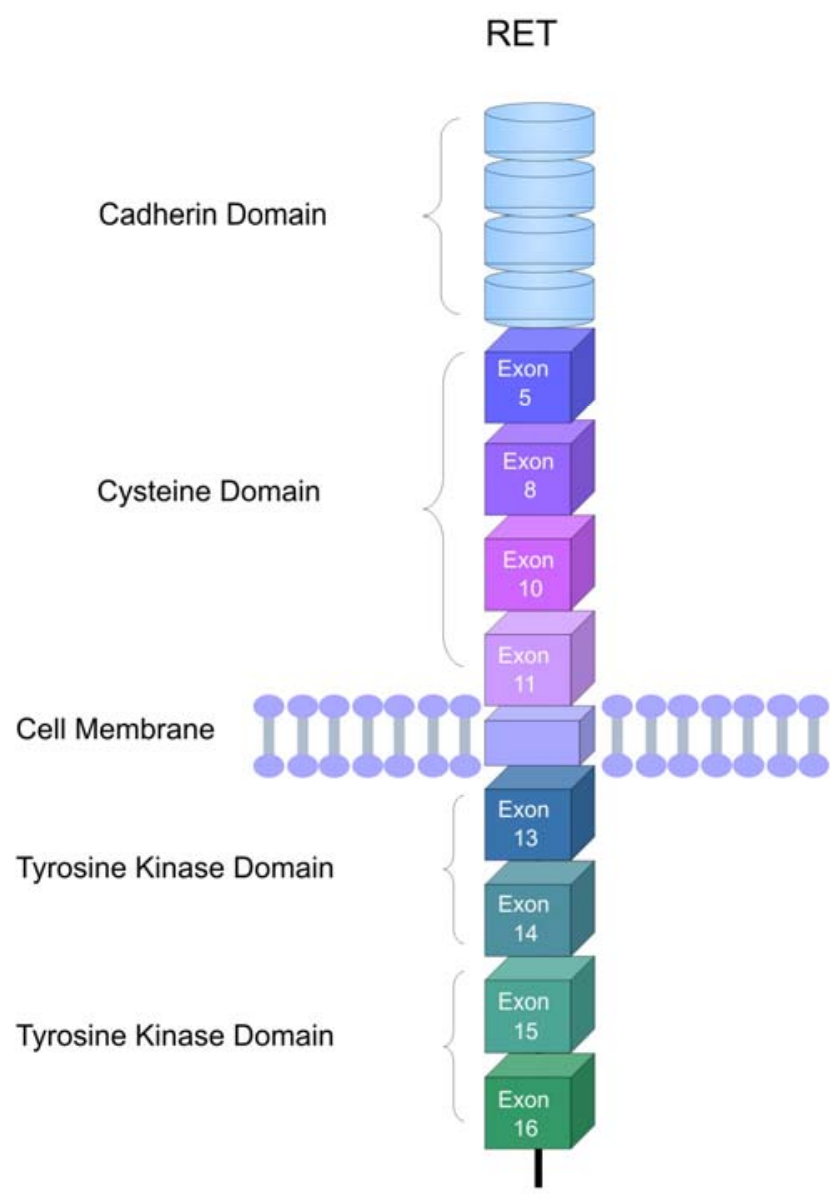

\section{RET Protein Activation}

The RET receptor tyrosine kinase is activated through a complex formed by the glial cell line-derived neurotrophic factor (GDNF) family of ligands and co-receptors. Under normal conditions, RET activation depends on the interaction of GFR $\alpha$ (GDNF Family $\alpha$ Receptor) co-receptors and their respective ligands GFLs (GDNF Family of Ligands). The GFR $\alpha$-ligand complex, together with the extracellular portion of RET, promotes autophosphorylation of the intracellular tyrosine residues [24,25].

The RET co-receptors are usually bound to the plasma membrane, but GFRs also occur in a soluble form, and can then activate RET in two distinct forms: cis or trans (Figure 2). The cis model for the RET activation hypothesis occurs when the GFL ligand binds to the GFR $\alpha$ co-receptor anchored on a 
lipid platform and later this complex promotes the approach of two RET molecules through the lipid platform, allowing the phosphorylation of the intracellular tyrosine residues. On the other hand, the trans model activation suggests that the GFL may also bind to the soluble form of GFR $\alpha$, stimulating the dimerization of RET outside the lipid platform, thus allowing its activation. Once activated, RET initiates the different intracellular pathways involving the regulation of processes such as differentiation, survival, proliferation, migration and cell chemotaxis [24,26].

Figure 2. Mechanisms of ligand-mediated RET activation. (A) In the cis model RET activation: the glial cell line-derived neurotrophic factor (GDNF) family of ligands (GFL) binds to membrane glycosylphosphatidylinositol-anchored GDNF-family coreceptors (GFR $\alpha)$. The activation leads to dimerization of RET and consequently activation of the intracellular signaling pathways; (B) In the trans model RET activation: the ligand binds to the soluble form of its coreceptor (GFR $\alpha$ ) and the ligand-GFR $\alpha$ complex brings together two inactive RET monomers. Ligand-induced activation induces dimerization and tyrosine phosphorylation of the RET receptor with downstream activation of several signal transduction pathways.



The molecular mechanism by which RET mutations trigger the neoplastic process was determined by elegant in vitro studies performed by Santoro et al. [27]. Briefly, under normal conditions, RET is only activated in the presence of GFR $\alpha /$ GFL complex, which on binding to the RET receptor promotes its dimerization and auto-phosphorylation of the intracellular signaling pathways. The presence of mutation in the extracellular domain, as found in MEN 2A, leads to the dimerization of RET even in the absence of the ligand, with consequent constitutive activation of the intracellular signaling 
pathways (Figure 3A). Mutations in the intracellular tyrosine-kinase domain, as found in MEN 2B, alter RET substrate specificity due to structural changes in this domain. Consequently, the mutated RET no longer needs dimerization to become active (Figure 3B) [28,29]. The activation of the RET protein appears to be an initial step in the oncogenic pathway in the tissues where it is expressed. Molecular evidence of other chromosomal abnormalities, such as loss of heterozygosity, most often at $1 p$ and $22 q$, suggest that additional cytogenetic events are probably involved $[11,30]$.

Figure 3. Characterization of RET oncogenic activation in MEN2 inherited cancer syndromes. (A) MEN 2A RET mutation leaves an unpaired cysteine residue in a RET monomer to form an aberrant intermolecular disulfide bond with another mutated monomer. The two mutated RET molecules are constitutively dimerized and activated; (B) MEN 2B RET mutation activates tyrosines in the kinase domain and alters its substrate specificity leading to aberrant phosphorylation of substrates of RET receptor.

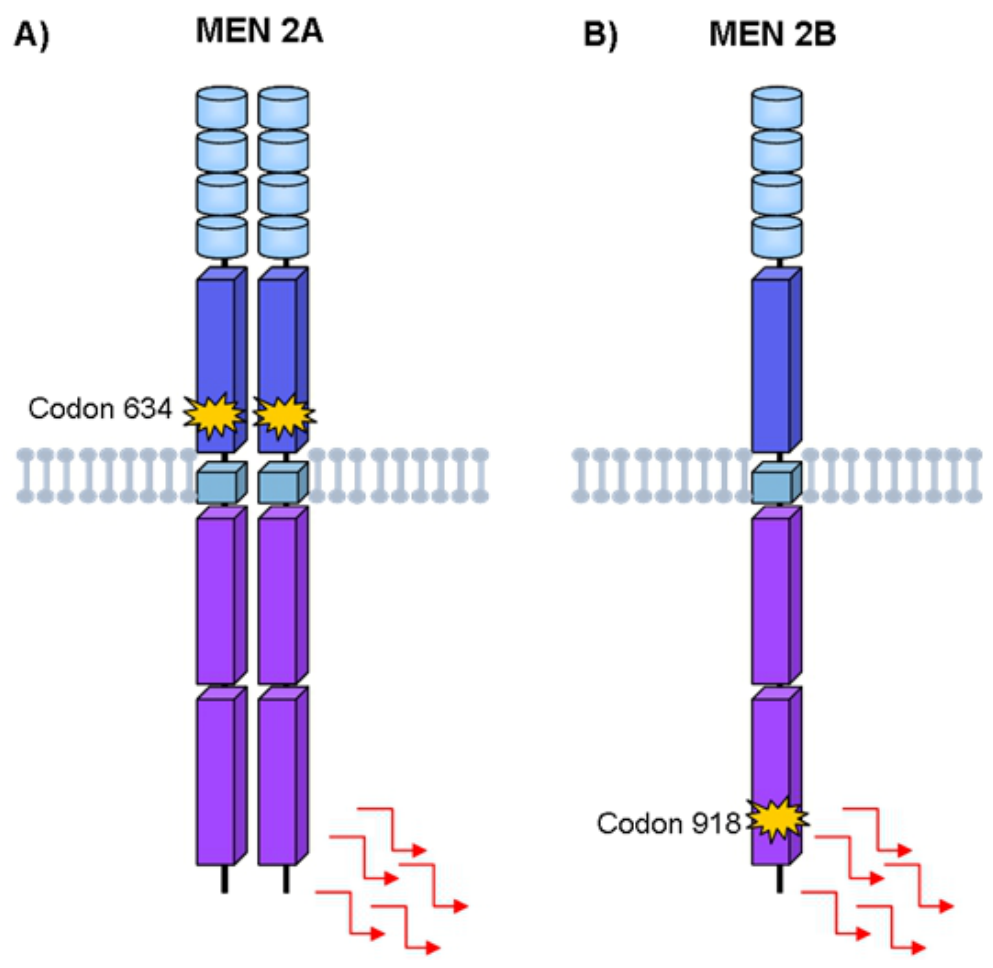

\section{Hereditary Medullary Thyroid Carcinoma}

Approximately 25\% of MTC cases occur as part of the inherited cancer syndrome of MEN 2 [7,31]. The MEN 2A subtype constitutes approximately $70 \%-80 \%$ of cases of MEN 2 and is characterized by the presence of MTC (95\%), pheochromocytoma (30-50\%) and hyperparathyroidism (HPT) (10-20\%). The MEN 2B syndrome accounts for about 5\% of the cases of MEN 2. The frequency of MTC is over $90 \%$, pheochromocytoma (45\%), ganglioneuromatosis $(100 \%)$ and marfanoid habitus $(65 \%)$ [11,32]. This syndrome is characterized by a single phenotype, which includes diffuse ganglioneuromatosis of the tongue, lips, eyes and gastrointestinal tract, long fingers and extremities, hyperextension of the joints and epiphyseal abnormalities. MTC in the setting of MEN 2B develops earlier and has a more aggressive course, occurring at a younger age compared with MTC in other MEN 2 subtypes [6,7]. The FMTC subtype constitutes approximately 10 to $20 \%$ of the cases of 
MEN 2 [11]. MTC is the only manifestation and thereby it is necessary to demonstrate the absence of a pheochromocytoma or hyperparathyroidism in two or more generations of the same family or the identification of related mutations to confirm that particular kindred have this syndrome. In these cases, the clinical presentation of MTC occurs later and the prognosis is more favorable (corresponding to older age at onset, often between 20 and 40 years) compared to the other forms of MTC [33].

\section{Germline RET Mutations and Disease Phenotype}

Several studies indicate a correlation among specific RET mutations (genotype) and age of onset, aggressiveness of MTC and the presence or absence of other endocrine neoplasms (phenotype) [11,34-36]. Several independent mutations in the RET at exons 5, 8, 10,11,13,14, 15 and 16, have been established as causative of MEN 2A, MEN 2B and FMTC [8-13].

The majority of families with MEN 2A (more than 90\%) present point mutations in the RET protooncogene (missense type), involving codons located in the extracellular domain of the receptor: 609, 611, 618 and 620 (exon 10) and 634 (exon 11). The most frequent mutations are located in codon 634, occurring in more than $60 \%$ of all genetically identified MTC [11,13,32,37]. Codon 634 mutations have been associated with the presence of pheochromocytoma and hyperparathyroidism [38], and rarely with CLA [39]. Nevertheless, there are a variety of phenotypic expressions in families with the same RET mutation $[9,11,12,35,38]$. Puñales et al. observed that the genotype C634R (TGC/Cys $\rightarrow$ CGC/Arg, exon 11) presented significantly more distant metastases at diagnosis than groups C634W $(\mathrm{Cys} / \mathrm{TGC} \rightarrow \mathrm{Trp} / \mathrm{TGG}$, exon 11) and C634Y (Cys/TGC $\rightarrow$ Tyr/TAC, exon 11), thus suggesting that a change of specific amino acids may modify the natural development of the disease [36]. A recent study evaluated the RET C634W-specific neoplastic risk and age-related penetrance profiles and found that penetrance is high for MTC ( $52 \%$ by age $30,83 \%$ by age 50 and $98 \%$ by age 70 ) and pheochromocytoma ( $20 \%$ by age $30,67 \%$ by age 50 and $92 \%$ by age 70 ) [40]. In contrast to well-defined risk profiles for carriers of the codon 634 mutations, consensual clinical guidelines for RET exon 10 mutation are still being defined. Risk profiles and penetrance estimations in MEN 2A caused by germline RET exon 10 mutations were recently analyzed by Frank-Raue et al. (2011) in a large multicenter study that included 340 subjects from 103 families. The authors observed that mutations affect mainly the cysteine codons $609,611,618$ and 620 and 50\% penetrance was achieved by the age of 36 years for MTC, by 68 years for pheochromocytoma, and by 82 years for HPT [41]. These data may facilitate risk assessment and genetic counseling for MTC.

MEN 2B occurs, in approximately 95\% of the cases, through a specific M918T mutation (exon 16), resulting in the structural change of the intracellular domain of the RET protein. In about $2-3 \%$ of patients with MEN 2B, the genotype A883F (GCT $\rightarrow$ TTT, exon 15) can be found [42,43]. In addition, a double mutation $\mathrm{V} 804 \mathrm{M} / \mathrm{Y} 806 \mathrm{C}$ at codon 804 (Val/GTG $\rightarrow$ Met/ATG, exon 14) and 806 $($ Tyr/TAC $\rightarrow$ Cys/TGC) in the same allele was described in a patient with MEN 2B. Patients presenting with "atypical" MEN 2B harboring the germline double point mutation in codons 804 and 904 (V804M and S904C) were also reported [44,45]. Mutations in codons 883 and 918 are associated with younger age of MTC onset and higher risk of metastases and disease-specific mortality $[11,31,46]$. 
In FMTC, germline mutations are distributed throughout the RET gene. Approximately $86-88 \%$ of FMTC families have mutations in one of the 5 cysteines in the extracellular domain of the RET gene in exons 10 (codons 609, 611, 618, 620) and exon 11 (codon 634) [12,47]. Substitutions in the intracellular domain of RET in exon 13 (codon 768, 790, 791), in exon 14 (codon 804 and 844) and in exon 15 (codon 891) are less frequent. Interestingly, the most frequent mutation in MEN 2A, C634R, has not been described in FMTC families [11,47-50].

Based on genotype-phenotype correlation studies, the American Thyroid Association (ATA) developed recommendations for age of prophylactic thyroidectomy in asymptomatic RET mutation carriers. The different mutations are classified into four risk categories according to the aggressiveness of the disease $(\mathrm{A}<\mathrm{B}<\mathrm{C}<\mathrm{D}$ ). Children with mutations associated with MEN 2B phenotype (ATA level D risk) are at highest risk for early development of MTC and should have thyroidectomy as soon as possible, preferably within the first year of life. Patients with codon 634 mutations (ATA level C risk) are also at higher risk for development of MTC at early ages and the prophylactic total thyroidectomy should be carried out before 5 years of age. In patients with ATA level A and B RET mutations (codons 768, 790, 791, 804, 891 and 609, 611, 618, 620, 630 respectively), the risk for MTC is moderate and the prophylactic total thyroidectomy may be delayed beyond the age of 5 years if there is a less aggressive MTC family history, a normal basal stimulated serum calcitonin and normal neck ultrasound [51].

\section{Sporadic Medullary Thyroid Carcinoma}

Sporadic MTC generally presents as a unifocal tumor or a palpable cervical lymph node. Diagnosis tends to be late, generally in the fifth or sixth decade of life [52]. Lymph node metastases are detected in at least $50 \%$ of these patients, while distant metastases occur in $\sim 20 \%$ of cases $[53,54]$. A minority of patients with MTC present systemic manifestations which include diarrhea, flushing, or painful bone metastases [6].

\section{Somatic RET Mutations and Disease Phenotype}

In sporadic MTC, somatic mutation in exon 16 of the RET (M918T) has been identified in 50-80\% of the patients [14-17]. Somatic mutations in codons 618,603, 634, 768, 804 and 883 and partial deletion of the RET gene have been identified in few tumors [53,54]. The presence of a somatic RET mutation correlates with a worse outcome for MTC patients, not only because of the higher probability of persistent disease, but also because of a lower survival rate in a long-term follow up [53,54].

The somatic RET mutations (exons 10, 11 e 16) have also been described in other endocrine tumors. Mutations associated with MEN 2A (codon 634 and 631) and 2B (codon 918) phenotype are also found in about $15-20 \%$ of sporadic pheochromocytomas $[55,56]$.

\section{Role of RET Polymorphisms in Medullary Thyroid Carcinoma}

Since the identification of the RET proto-oncogene as the susceptibility gene for hereditary MTC, major advances have been observed in studies concerning the pathogenesis of MTC and associated neoplasias $[9,13]$. However, certain aspects of the disease, such as the clinical heterogeneity observed 
in individuals who have the same mutation, are not yet well understood [36,57,58]. As to sporadic MTC, the picture is slightly more obscure, since RET somatic mutations are not found in all cases $[15,21,46,59]$ and appear not to occur uniformly among the different subpopulations of cells in the tumor $[14,15,60]$. In recent years, several authors have investigated whether the presence of variant sequences or polymorphisms could be associated with susceptibility for the development or progression of MTC. These studies have described an increased prevalence of the RET polymorphisms G691S (exon 11, rs1799939), L769L (exon 13, rs1800861), S836S (exon 14, rs1800862), and S904S (exon 15, rs1800863) in individuals with hereditary or sporadic MTC when compared with the population [17,57,60-62]. Below, we will discuss the main aspects related to these polymorphisms and susceptibility to MTC development.

\subsection{RET G691S and S904S Polymorphisms}

The non synonymous variant G691S (Gly/GGT $\rightarrow$ Ser/AGT) has been associated with developing sporadic MTC in two larger studies [61,63]. In an Italian population it was demonstrated that the frequency of G691S polymorphism was greater in patients with sporadic MTC compared to the controls $(27.8 \%$ vs. $18.9 \% P=0.029)$. Moreover, the authors observed that G691S polymorphism presents a positive significant co-segregation with S904S (SerTCC $\rightarrow$ SerTCG) polymorphism [61]. Additionally, Cebrian et al. (2005), have demonstrated a 1.5 to 2.5 -fold increase in the relative risk for the development of MTC in patients who presented polymorphisms in exons 11 (G691S), 15 (S904S) and $19(\mathrm{STOP}+388 \mathrm{bp})$ [63]. These two studies postulated, through a functional assessment of RET transcription and splicing, that G691S could be the functional variant, but the results were inconclusive [61,63]. Fugazzola et al. (2008) also tested the functional activity of the RET G691S variant and show that the RET9-G691S protein was overrepresented when compared to RET9-WT. However, no transforming activity was observed [64].

Robledo et al., in 2003, also described a strong co-segregation between polymorphisms G691S and S904S, reporting a strong linkage disequilibrium between these polymorphisms. Additionally, it was also demonstrated that haplotype G691S/S904S, in homozygosis, was more prevalent in patients with MEN 2A compared to the control group, suggesting a role as a gene with low penetrance for this variant. Furthermore, the authors observed that this variant (G691S/S904S) could modify the age of onset of MTC patients [57]. However, these data were not replicated in a large sample of European population [65].

Although several studies have found an association between G691S/S904S polymorphisms and MTC, some authors did not observe a difference in the frequency of this variant between MTC patients and the general population [17,66-68]. Wohllk et al. analyzed 50 Chilean patients with sporadic tumors and 50 controls of similar ethnic origins, and showed a similar frequency of the RET G691S/S904S variants for cases and controls [69]. More recently, these negative results were replicated in Polish, Brazilian and Indian populations [17,67,68].

\subsection{RET L769L Polymorphism}

In 2001, a study conducted by Wiench et al. reported that patients with sporadic MTC and under the age of 30 years presented a higher frequency of the variant L769L (LeuCTT $\rightarrow$ LeuCTG) allele 
than those diagnosed between $31-45$ years (36\% vs. $15 \%, P=0.04)$, suggesting that this polymorphism was associated with younger age at diagnosis. However, the absence of a control group diminished the relevance of this observation [58]. Interestingly, Magalhães et al. (2004) observed that a patient harboring a V804M mutation, classically associated with late-onset and lower aggressiveness MTC, associated with the L769L polymorphism presented clinically evident MTC at 32 years of age, in contrast to her asymptomatic mother, who had only the V804M mutation and had MTC diagnosed by fine-needle aspiration biopsy at 60 years of age. The authors suggest that polymorphism L769L of $R E T$ proto-oncogene may be related to younger age at the onset of disease [70].

An association between the presence of L769L polymorphism and F769Y mutation was reported in FMTC patients for Baumgartner-Parzer et al. In this study, the authors deduced from pedigree analyses that the F791Y mutation and L769L polymorphism are located on the same allele and speculated whether the presence of this polymorphism could predispose the respective allele for the occurrence of a F791Y de novo mutation or would modulate the disease phenotype [66].

More recently, the presence of polymorphism L769L in the RET gene was associated with predisposition to the development of sporadic MTC and also younger age at onset of MTC in carriers of the homozygous polymorphic variant L769L. The authors also demonstrated that this variant modifies the structure of mRNA and could lead to changes in kinase activity and/or specificity of the protein [68].

Conversely, other studies did not show an association between the L769L polymorphism and MTC $[60,61,63,69]$. Berard et al. analyzed the presence of the L769L polymorphism in patients with sporadic MTC and controls, and found no difference in the distribution of these polymorphisms between the groups analyzed [71]. Accordingly, Siqueira et al. did not observe the influence of neutral RET L769L variants on clinical and oncological features in individuals with hereditary or sporadic MTC [17]. Recently, a study performed in Indian patients also failed to demonstrate a difference in the frequency of this allele in MTC patients and control group [67].

\subsection{RET S836S Polymorphism}

Gimm et al., in 1999, identified an association between the RET polymorphisms S836S $($ SerAGC $\rightarrow$ SerAGT) and sporadic MTC. The authors reported a higher frequency of the variant allele in the group with MTC compared with the control group (9.0 vs. 3.7\% $P=0.03$ ) [60]. These findings were confirmed in a Spanish population [72]

A recent study investigated the influence of the neutral RET S836S variants on the clinical presentation of hereditary or sporadic MTC in a large cohort of Brazilian patients. The variant S836S was associated with the early onset of the disease and a higher risk for the development of lymph node and distant metastases $(P=0.002$ and $P=0.001$, respectively) in patients with hereditary or sporadic MTC [17].

Other association studies, however, have failed to show differences as to the presence of S836S polymorphisms between patients with sporadic MTC and controls [61,63,68,69]. Wiench et al. in a Polish population and Berard et al. in French patients observed a similar frequency of the RET S836S variants for cases and controls [58,71]. Similar data were found in other populations $[61,63,68,69]$. Study performed in India did not observe significant differences in the frequency of this polymorphic 
allele in the patients and control group. Interestingly, the prevalence of the RET polymorphisms in the Indian population was significantly higher than those observed in Germans, Italians, French, Spanish and Hungarians $(P>0.002)[67]$.

\subsection{Other RET Variants}

Besides the variants already mentioned, other polymorphisms have also been associated with MTC. A study showed higher frequency of intron 14 (IVS14-24; rs2472737) polymorphism in the group with elevated serum calcitonin concentrations $(P=0.016)$ and in patients with sporadic MTC $(P<0.001)$, when compared with the control group with normal calcitonin levels. However, further studies are necessary to characterize a potential role of this RET sequence variant in the development of sporadic MTC [66].

Recently, two other variants of RET were identified (IVS1-126 G > T; rs2565206) and (IVS8+82 A > G; rs3026750 and 85-86 insC; rs3482797), and associated with phenotypic variability in patients with mutation G533C. In this study, the authors found an association between variant IVS1-126 G $>\mathrm{T}$ and age at diagnosis of MTC. On the other hand, variant (IVS8+82 A > G; InsC 85-86) was associated with the presence of lymph node metastases at the time of diagnosis. Analyses in silico suggest that this variant may induce abnormal splicing, postulating that variant (IVS8+82 A > G; 85-86 InsC) could interrupt and/or create an exonic splicing site, thus leading to the synthesis of an altered protein [73]. In another study, a polymorphism in exon 2 (GCG $\rightarrow$ GCA), which encodes an alanine (A45A), occurred at a lower frequency among the cases of MTC and, according to the authors, it could confer a protective allele against the development of MTC [63].

Taken together, these data point to a potential influence of RET variants in the development and progression of MTC. Tables 1 and 2 summarize the main findings of the studies on the role of RET polymorphisms in MTC.

Table 1. Role of the RET variants in hereditary medullary thyroid cancer.

\begin{tabular}{|c|c|c|c|c|c|c|c|c|}
\hline$R E T$ variant & Author & Cases & Controls & $\boldsymbol{P}$ & $\begin{array}{c}\text { Frequency } \\
\text { (cases vs. } \\
\text { controls) }\end{array}$ & $\begin{array}{c}\text { Genotyping } \\
\text { platform }\end{array}$ & Conclusion & Population \\
\hline \multirow{4}{*}{$\begin{array}{c}\text { G691S } \\
(\text { rs1799939) }\end{array}$} & $\begin{array}{l}\text { Robledo } \\
\text { (2003) }\end{array}$ & 198 & 653 & 0.037 & - & sequencing & $\begin{array}{l}\text { Associated with the } \\
\text { presence of MTC } \\
\text { in younger } \\
\text { individuals. }\end{array}$ & Spanish \\
\hline & $\begin{array}{l}\text { Lesueur } \\
(2006)\end{array}$ & 384 & - & - & - & Taqman & $\mathrm{N} / \mathrm{A}$ & European \\
\hline & $\begin{array}{l}\text { Tamanah } \\
\text { a (2009) }\end{array}$ & $77^{\mathrm{a}}$ & 100 & 0.048 & $0 ; 4$ & RFLP & $\begin{array}{l}\text { Underrepresented } \\
\text { in G533C-arriers. }\end{array}$ & Brazilian \\
\hline & $\begin{array}{l}\text { Sharma }{ }^{b} \\
(2011)\end{array}$ & 51 & 50 & NS & $49 ; 48$ & sequencing & N/A & Indian \\
\hline $\begin{array}{c}\text { L769L } \\
(\text { rs1800861) }\end{array}$ & $\begin{array}{l}\text { Sharma } \\
(2011)\end{array}$ & 51 & 50 & NS & $45 ; 58$ & sequencing & N/A & Indian \\
\hline
\end{tabular}


Table 1. Cont.

\begin{tabular}{|c|c|c|c|c|c|c|c|c|}
\hline$R E T$ variant & Author & Cases & Controls & $\boldsymbol{P}$ & $\begin{array}{l}\text { Frequency } \\
\text { (cases vs. } \\
\text { controls) }\end{array}$ & $\begin{array}{c}\text { Genotyping } \\
\text { platform }\end{array}$ & Conclusion & Population \\
\hline \multirow{3}{*}{$\begin{array}{c}\mathbf{S 8 3 6 S} \\
\text { (rs1800862) }\end{array}$} & $\begin{array}{l}\text { Tamanah } \\
\text { a (2009) }\end{array}$ & 77 a & 100 & 0.008 & $16.9 ; 4$ & RFLP & $\begin{array}{l}\text { Over-represented } \\
\text { in G533C-carriers. }\end{array}$ & Brazilian \\
\hline & $\begin{array}{l}\text { Siqueira } \\
\text { (2010) }\end{array}$ & 88 & - & - & $7.95 ;-$ & RFLP & $\begin{array}{c}\text { Associated with } \\
\text { early onset and } \\
\text { increased risk for } \\
\text { metastatic disease. }\end{array}$ & Brazilian \\
\hline & $\begin{array}{c}\text { Sharma b } \\
(2011) \\
\end{array}$ & 51 & 50 & NS & $25 ; 22$ & sequencing & $\mathrm{N} / \mathrm{A}$ & Indian \\
\hline \multirow{3}{*}{$\begin{array}{c}\text { S904S } \\
(\text { rs1800863) }\end{array}$} & $\begin{array}{l}\text { Lesueur } \\
(2006)\end{array}$ & 384 & - & - & - & Taqman & N/A & European \\
\hline & $\begin{array}{c}\text { Sharma b } \\
\text { (2011) }\end{array}$ & 51 & 50 & NS & $25 ; 22$ & sequencing & N/A & Indian \\
\hline & $\begin{array}{l}\text { Tamanah } \\
\mathrm{a}(2009)\end{array}$ & 77 a & 100 & 0.048 & $0 ; 4$ & RFLP & $\begin{array}{l}\text { Underrepresented } \\
\text { in G533C-carriers. }\end{array}$ & Brazilian \\
\hline $\begin{array}{c}\text { IVS1-126 } \\
\text { G }>\text { T } \\
(\text { rs2565206) }\end{array}$ & $\begin{array}{l}\text { Tamanah } \\
\text { a (2009) }\end{array}$ & 77 a & 100 & 0.002 & $1.3 ; 0$ & RFLP & $\begin{array}{l}\text { Associated with } \\
\text { younger age at } \\
\text { diagnosis. }\end{array}$ & Brazilian \\
\hline $\begin{array}{c}\text { IVS8+82 } \\
\text { A>G; } \\
85-86 \text { insC } \\
(\mathbf{r s 3 0 2 6 7 5 0 )}\end{array}$ & $\begin{array}{c}\text { Tamanah } \\
\text { a (2009) }\end{array}$ & 77 a & - & 0.019 & - & RFLP & $\begin{array}{l}\text { Associated with } \\
\text { lymph node } \\
\text { metastases. Could } \\
\text { induce abnormal } \\
\text { splicing. }\end{array}$ & Brazilian \\
\hline
\end{tabular}

${ }^{a}$ Study performed in patients with RET G533C mutation; ${ }^{\mathrm{b}}$ The study included hereditary and sporadic MTC patients; N/A: no association was found.

Table 2. Role of the RET variants in sporadic medullary thyroid cancer.

\begin{tabular}{|c|c|c|c|c|c|c|c|c|}
\hline$R E T$ variant & Author & Cases & Controls & $\boldsymbol{P}$ & $\begin{array}{c}\text { Frequency } \\
\text { (cases vs. } \\
\text { controls) }\end{array}$ & $\begin{array}{c}\text { Genotyping } \\
\text { platform }\end{array}$ & Conclusion & Population \\
\hline \multirow{4}{*}{$\begin{array}{c}\text { G691S/S904S } \\
(\mathrm{rs1799939)/} \\
(\mathrm{rs} 1800863)\end{array}$} & $\begin{array}{l}\text { Elisei } \\
(2004)\end{array}$ & 106 & 106 & 0.029 & $27.8 ; 18.8$ & RFLP & $\begin{array}{l}\text { Higher frequency } \\
\text { in MTC patients. } \\
\text { Does not } \\
\text { influence RET } \\
\text { mRNA } \\
\text { expression }\end{array}$ & European \\
\hline & & & & & & & Associated with & \\
\hline & $\begin{array}{c}\text { Cebrian }{ }^{\mathrm{a}} \\
(2005)\end{array}$ & 120 & 528 & 0.004 & $27 ; 18$ & TaqMan & $\begin{array}{l}\text { higher risk for } \\
\text { development of } \\
\text { MTC. Does not } \\
\text { affect the splicing } \\
\text { of RET }\end{array}$ & British \\
\hline & $\begin{array}{l}\text { Wohllk } \\
(2005)\end{array}$ & 50 & 50 & NS & $25 ; 25$ & sequencing & N/A & Chilean \\
\hline
\end{tabular}


Table 2. Cont.

\begin{tabular}{|c|c|c|c|c|c|c|c|c|}
\hline$R E T$ variant & Author & Cases & Controls & $\boldsymbol{P}$ & $\begin{array}{l}\text { Frequency } \\
\text { (cases vs. } \\
\text { controls) }\end{array}$ & $\begin{array}{c}\text { Genotyping } \\
\text { platform }\end{array}$ & Conclusion & Population \\
\hline \multirow{4}{*}{$\begin{array}{c}\text { L769L } \\
(\text { rs1800861) }\end{array}$} & $\begin{array}{l}\text { Wiench } \\
(2001)\end{array}$ & $116^{\mathrm{b}}$ & - & $0.04^{\mathrm{b}}$ & $36 ; 15$ & sequencing & $\begin{array}{l}\text { Associated with } \\
\text { the presence of } \\
\text { MTC in younger } \\
\text { individuals }\end{array}$ & Polish \\
\hline & $\begin{array}{l}\text { Sromek } \\
(2010)\end{array}$ & 217 & 420 & $0.039^{\mathrm{c}}$ & $48.3 ; 39.5^{\mathrm{c}}$ & Sequencing & $\begin{array}{l}\text { Associated with } \\
\text { the presence of } \\
\text { MTC in younger } \\
\text { individuals (in } \\
\text { homozygosis). } \\
\text { Could influence } \\
\text { RET mRNA } \\
\text { structure }\end{array}$ & Polish \\
\hline & $\begin{array}{l}\text { Berard } \\
(2004)\end{array}$ & 184 & 174 & NS & $22.3 ; 25.9$ & sequencing & N/A & French \\
\hline & $\begin{array}{l}\text { Wohllk } \\
(2005)\end{array}$ & 50 & 50 & NS & $24 ; 23$ & sequencing & N/A & Chilean \\
\hline \multirow{5}{*}{$\begin{array}{c}\text { S836S } \\
\text { (rs1800862) }\end{array}$} & $\begin{array}{l}\text { Gimm } \\
(1999)\end{array}$ & 50 & 70 & 0.03 & $9 ; 3.7$ & RFLP & $\begin{array}{l}\text { More frequent in } \\
\text { MTC patients }\end{array}$ & $\begin{array}{l}\text { German- } \\
\text { American }\end{array}$ \\
\hline & $\begin{array}{l}\text { Ruiz } \\
(2001)\end{array}$ & 32 & 250 & 0.04 & $9.3 ; 3.6$ & RFLP & $\begin{array}{l}\text { Associated with } \\
\text { higher risk for } \\
\text { development of } \\
\text { MTC }\end{array}$ & Spanish \\
\hline & $\begin{array}{l}\text { Siqueira } \\
(2010)\end{array}$ & 81 & 80 & 0.01 & $10.5 ; 3.2$ & RFLP & $\begin{array}{l}\text { Associated with } \\
\text { early onset and } \\
\text { increased risk for } \\
\text { metastatic disease }\end{array}$ & Brazilian \\
\hline & $\begin{array}{l}\text { Berard } \\
(2004)\end{array}$ & 184 & 174 & NS & $6.5 ; 5.2$ & sequencing & N/A & French \\
\hline & $\begin{array}{l}\text { Wohllk } \\
(2005)\end{array}$ & 50 & 50 & NS & $6 ; 1$ & sequencing & N/A & Chilean \\
\hline \multirow[b]{2}{*}{$\begin{array}{c}\text { S904S } \\
\text { (rs1800863) }\end{array}$} & $\begin{array}{l}\text { Wohllk } \\
(2005)\end{array}$ & 50 & 50 & NS & $27 ; 28$ & sequencing & N/A & Chilean \\
\hline & $\begin{array}{l}\text { Cebrian } \\
(2005)\end{array}$ & 125 & 528 & 0.005 & $26.4 ; 15.5$ & TaqMan & $\begin{array}{l}\text { Associated with } \\
\text { higher risk for } \\
\text { development of } \\
\text { MTC }\end{array}$ & British \\
\hline $\begin{array}{c}\text { STOP+388pb } \\
\text { G>A } \\
(\text { rs3026782 }\end{array}$ & $\begin{array}{c}\text { Cebrian } \\
(2005)\end{array}$ & 123 & 522 & 0.005 & $26.4 ; 15.5$ & TaqMan & $\begin{array}{l}\text { Associated with } \\
\text { higher risk for } \\
\text { development of } \\
\text { MTC }\end{array}$ & British \\
\hline $\begin{array}{l}\mathbf{A} 45 \mathrm{~A} \text { G }>A \\
(\mathrm{rs} 1800858)\end{array}$ & $\begin{array}{c}\text { Cebrian } \\
(2005)\end{array}$ & 126 & 525 & 0.04 & $21 ; 27.9$ & TaqMan & $\begin{array}{c}\text { Suggest } \\
\text { protective effect }\end{array}$ & British \\
\hline
\end{tabular}

${ }^{a}$ Study did not confirm the previously described association between G691S and S904S; ${ }^{\text {b }}$ The comparison was performed between patients aged below and above 30 years; ${ }^{\mathrm{c}}$ Frequency of heterozygous change L769L.N/A: no association was found. 


\subsection{Possible Mechanisms of Action for RET Polymorphism in Medullary Thyroid Carcinoma}

So far it is not known how polymorphisms exert their effects on the development or progression of MTC and the mechanistic explanation is still speculative. A quantitative study of RET mRNA levels in tumor tissues of individuals with MTC did not show a difference in the expression in patients with and without G691S/S904S polymorphism [61]. The S836S polymorphism failed to affect DNA-protein binding, transcript stability, or RNA splicing and editing [74]. Other hypothesis is that bases exchange in the DNA molecule could interrupt and/or create a splicing site, leading to the synthesis of an altered protein, or else, that the modified nucleotide is in a state of linkage disequilibrium with an as yet unknown functional variant $[60,73]$. It has also been proposed a specific effect of G691S polymorphism on RET dimerization on MEN 2A patients harboring the 634 mutation [57]. Potential changes on mRNA structure due to the presence of RET polymorphisms have also been evaluated. The simplest prediction of mRNA structure is a prediction of thermodynamic stable structure, MFE (minimal free energy) structure. Bioinformatics analysis showed that differences in MFE between wild types and mutants are $<5 \%$ in the case of polymorphisms S904S and S836S and mutations Y791F and C634R. No effect on MFE was visible also in the combination of C634R and L769L polymorphism. However, the difference was noticeable in the case of exon 13. The L769L variant reduces the energy of the wild type by $17 \%$ and the mutant Y791F by $7 \%$, leading the authors to conclude that the L769L polymorphism reduces the MFE of small RET mRNA [68]. Finally, in silico analysis revealed that the IVS1-126 G>T genetic variant creates a new binding site for NFAT transcription factor (nuclear factor of activated T-cells) [75]. The NFAT family of proteins has been found to be involved in cell cycle regulation, cell differentiation, cell survival, angiogenesis, tumor cell invasion, and metastasis [76], which may explain the association of this variant with disease progression [73].

\section{Conclusion}

In summary, since the recognition of the RET proto-oncogene as the susceptibility gene for hereditary MTC several decades ago, advances have taken place in understanding pathogenesis of MTC and associated neoplasias. Nevertheless, certain aspects of the disease, such as the clinical heterogeneity seen in individuals harboring the same mutation have not yet been well understood. Polymorphisms in the RET gene are commonly associated with MTC and may partially explain the large clinical heterogeneity observed in MEN 2A patients. An entire set of data obtained from clinical studies indicates a potential role of RET polymorphisms in the development of sporadic MTC. However, in contrast, several others failed to demonstrate any association between these RET variants and MTC development or disease progression. Although differences in ethnic background or methodological flaws might be potential causes for the different results described, the mechanism underlying the positive associations is still lacking which stimulates further controversy. Since the contribution of a single variant to a disease is determined by the prevalence of the implicated allele and the magnitude of the association with the condition, the results summarized here might indicate the need for large multicenter studies to confirm or rule out a role of these variants as a cause or modifying agent in this rare disease. 


\section{References}

1. Hazard, J.B.; Hawk, W.A.; Crile, G., Jr. Medullary (solid) carcinoma of the thyroid; a clinicopathologic entity. J. Clin. Endocrinol. Metab. 1959, 19, 152-161.

2. Gilliland, F.D.; Hunt, W.C.; Morris, D.M.; Key, C.R. Prognostic factors for thyroid carcinoma. A population-based study of 15,698 cases from the Surveillance, Epidemiology and End Results (SEER) program 1973-1991. Cancer 1997, 79, 564-573.

3. Raue, F.; Kotzerke, J.; Reinwein, D.; Schroder, S.; Roher, H.D.; Deckart, H.; Hofer, R.; Ritter, M.; Seif, F.; Buhr, H.; et al. Prognostic factors in medullary thyroid carcinoma: evaluation of 741 patients from the German Medullary Thyroid Carcinoma Register. Clin. Investig. 1993, 71, 7-12.

4. Saad, M.F.; Ordonez, N.G.; Rashid, R.K.; Guido, J.J.; Hill, C.S., Jr.; Hickey, R.C.; Samaan, N.A. Medullary carcinoma of the thyroid. A study of the clinical features and prognostic factors in 161 patients. Medicine (Baltimore) 1984, 63, 319-342.

5. Girelli, M.E.; Nacamulli, D.; Pelizzo, M.R.; De Vido, D.; Mian, C.; Piccolo, M.; Busnardo, B. Medullary thyroid carcinoma: clinical features and long-term follow-up of seventy-eight patients treated between 1969 and 1986. Thyroid 1998, 8, 517-523.

6. Kebebew, E.; Ituarte, P.H.; Siperstein, A.E.; Duh, Q.; Clark, O.H. Medullary thyroid cancer. Curr. Treat. Opt. Oncol. 2000, 1, 359-367.

7. Modigliani, E.; Cohen, R.; Campos, J.M.; Conte-Devolx, B.; Maes, B.; Boneu, A.; Schlumberger, M.; Bigorgne, J.C.; Dumontier, P.; Leclerc, L.; Corcuff, B.; Guilhem, I. Prognostic factors for survival and for biochemical cure in medullary thyroid carcinoma: results in 899 patients. The GETC Study Group. Groupe d'etude des tumeurs a calcitonine. Clin. Endocrinol. (Oxf) 1998, 48, 265-273.

8. Da Silva, A.M.; Maciel, R.M.; Da Silva, M.R.; Toledo, S.R.; De Carvalho, M.B.; Cerutti, J.M. A novel germ-line point mutation in $R E T$ exon 8 (Gly(533)Cys) in a large kindred with familial medullary thyroid carcinoma. J. Clin. Endocrinol. Metab. 2003, 88, 5438-5443.

9. Donis-Keller, H.; Dou, S.; Chi, D.; Carlson, K.M.; Toshima, K.; Lairmore, T.C.; Howe, J.R.; Moley, J.F.; Goodfellow, P.; Wells, S.A., Jr. Mutations in the RET proto-oncogene are associated with MEN 2A and FMTC. Hum. Mol. Genet. 1993, 2, 851-856.

10. Dvorakova, S.; Vaclavikova, E.; Duskova, J.; Vlcek, P.; Ryska, A.; Bendlova, B. Exon 5 of the RET proto-oncogene: A newly detected risk exon for familial medullary thyroid carcinoma, a novel germ-line mutation Gly321Arg. J. Endocrinol. Invest. 2005, 28, 905-909.

11. Eng, C.; Clayton, D.; Schuffenecker, I.; Lenoir, G.; Cote, G.; Gagel, R.F.; van Amstel, H.K.; Lips, C.J.; Nishisho, I.; Takai, S.I.; et al. The relationship between specific RET proto-oncogene mutations and disease phenotype in multiple endocrine neoplasia type 2. International RET mutation consortium analysis. J. Am. Med. Assoc. 1996, 276, 1575-1579.

12. Mulligan, L.M.; Eng, C.; Healey, C.S.; Clayton, D.; Kwok, J.B.; Gardner, E.; Ponder, M.A.; Frilling, A.; Jackson, C.E.; Lehnert, H.; et al. Specific mutations of the RET proto-oncogene are related to disease phenotype in MEN 2A and FMTC. Nat. Genet. 1994, 6, 70-74.

13. Mulligan, L.M.; Kwok, J.B.; Healey, C.S.; Elsdon, M.J.; Eng, C.; Gardner, E.; Love, D.R.; Mole, S.E.; Moore, J.K.; Papi, L.; et al. Germ-line mutations of the RET proto-oncogene in multiple endocrine neoplasia type 2A. Nature 1993, 363, 458-460. 
14. Eng, C.; Mulligan, L.M.; Healey, C.S.; Houghton, C.; Frilling, A.; Raue, F.; Thomas, G.A.; Ponder, B.A. Heterogeneous mutation of the RET proto-oncogene in subpopulations of medullary thyroid carcinoma. Cancer Res. 1996, 56, 2167-2170.

15. Marsh, D.J.; Learoyd, D.L.; Andrew, S.D.; Krishnan, L.; Pojer, R.; Richardson, A.L.; Delbridge, L.; Eng, C.; Robinson, B.G. Somatic mutations in the RET proto-oncogene in sporadic medullary thyroid carcinoma. Clin. Endocrinol. (Oxf) 1996, 44, 249-257.

16. Romei, C.; Elisei, R.; Pinchera, A.; Ceccherini, I.; Molinaro, E.; Mancusi, F.; Martino, E.; Romeo, G.; Pacini, F. Somatic mutations of the RET protooncogene in sporadic medullary thyroid carcinoma are not restricted to exon 16 and are associated with tumor recurrence. J. Clin. Endocrinol. Metab. 1996, 81, 1619-1622.

17. Siqueira, D.R.; Romitti, M.; da Rocha, A.P.; Ceolin, L.; Meotti, C.; Estivalet, A.; Punales, M.K.; Maia, A.L. The RET polymorphic allele S836S is associated with early metastatic disease in patients with hereditary or sporadic medullary thyroid carcinoma. Endocr. Relat. Cancer 2010, 17, 953-963.

18. Takahashi, M.; Ritz, J.; Cooper, G.M. Activation of a novel human transforming gene, RET, by DNA rearrangement. Cell 1985, 42, 581-588.

19. Ishizaka, Y.; Itoh, F.; Tahira, T.; Ikeda, I.; Sugimura, T.; Tucker, J.; Fertitta, A.; Carrano, A.V.; Nagao, M. Human RET proto-oncogene mapped to chromosome 10q11.2. Oncogene 1989, 4, 1519-1521.

20. Takahashi, M.; Buma, Y.; Hiai, H. Isolation of RET proto-oncogene cDNA with an amino-terminal signal sequence. Oncogene 1989, 4, 805-806.

21. Hofstra, R.M.; Landsvater, R.M.; Ceccherini, I.; Stulp, R.P.; Stelwagen, T.; Luo, Y.; Pasini, B.; Hoppener, J.W.; van Amstel, H.K.; Romeo, G.; et al. A mutation in the RET proto-oncogene associated with multiple endocrine neoplasia type $2 \mathrm{~B}$ and sporadic medullary thyroid carcinoma. Nature 1994, 367, 375-376.

22. Myers, S.M.; Eng, C.; Ponder, B.A.; Mulligan, L.M. Characterization of RET proto-oncogene 3' splicing variants and polyadenylation sites: A novel $C$-terminus for RET. Oncogene 1995, 11, 2039-2045.

23. Takahashi, M.; Asai, N.; Iwashita, T.; Isomura, T.; Miyazaki, K.; Matsuyama, M. Characterization of the RET proto-oncogene products expressed in mouse L cells. Oncogene 1993, 8, 2925-2929.

24. Jing, S.; Wen, D.; Yu, Y.; Holst, P.L.; Luo, Y.; Fang, M.; Tamir, R.; Antonio, L.; Hu, Z.; Cupples, R.; et al. GDNF-induced activation of the RET protein tyrosine kinase is mediated by GDNFRalpha, a novel receptor for GDNF. Cell 1996, 85, 1113-1124.

25. Kjaer, S.; Ibanez, C.F. Identification of a surface for binding to the GDNF-GFR alpha 1 complex in the first cadherin-like domain of RET. J. Biol. Chem. 2003, 278, 47898-47904.

26. Yu, T.; Scully, S.; Yu, Y.; Fox, G.M.; Jing, S.; Zhou, R. Expression of GDNF family receptor components during development: implications in the mechanisms of interaction. J. Neurosci. 1998, 18, 4684-4696.

27. Santoro, M.; Carlomagno, F.; Romano, A.; Bottaro, D.P.; Dathan, N.A.; Grieco, M.; Fusco, A.; Vecchio, G.; Matoskova, B.; Kraus, M.H.; et al. Activation of RET as a dominant transforming gene by germline mutations of MEN2A and MEN2B. Science 1995, 267, 381-383. 
28. Borrello, M.G.; Smith, D.P.; Pasini, B.; Bongarzone, I.; Greco, A.; Lorenzo, M.J.; Arighi, E.; Miranda, C.; Eng, C.; Alberti, L.; et al. RET activation by germline MEN2A and MEN2B mutations. Oncogene 1995, 11, 2419-2427.

29. Carlson, K.M.; Dou, S.; Chi, D.; Scavarda, N.; Toshima, K.; Jackson, C.E.; Wells, S.A., Jr.; Goodfellow, P.J.; Donis-Keller, H. Single missense mutation in the tyrosine kinase catalytic domain of the RET protooncogene is associated with multiple endocrine neoplasia type $2 \mathrm{~B}$. Proc. Natl. Acad. Sci. USA 1994, 91, 1579-1583.

30. Mulligan, L.M.; Gardner, E.; Smith, B.A.; Mathew, C.G.; Ponder, B.A. Genetic events in tumour initiation and progression in multiple endocrine neoplasia type 2. Genes Chromosom. Cancer 1993, 6, 166-177.

31. Pelizzo, M.R.; Boschin, I.M.; Bernante, P.; Toniato, A.; Piotto, A.; Pagetta, C.; Nibale, O.; Rampin, L.; Muzzio, P.C.; Rubello, D. Natural history, diagnosis, treatment and outcome of medullary thyroid cancer: 37 years experience on 157 patients. Eur. J. Surg. Oncol. 2007, 33, 493-497.

32. Mulligan, L.M.; Marsh, D.J.; Robinson, B.G.; Schuffenecker, I.; Zedenius, J.; Lips, C.J.; Gagel, R.F.; Takai, S.I.; Noll, W.W.; Fink, M.; et al. Genotype-phenotype correlation in multiple endocrine neoplasia type 2: report of the International RET Mutation Consortium. J. Intern. Med. 1995, 238, 343-346.

33. Farndon, J.R.; Leight, G.S.; Dilley, W.G.; Baylin, S.B.; Smallridge, R.C.; Harrison, T.S.; Wells, S.A., Jr. Familial medullary thyroid carcinoma without associated endocrinopathies: a distinct clinical entity. Br. J. Surg. 1986, 73, 278-281.

34. Frank-Raue, K.; Buhr, H.; Dralle, H.; Klar, E.; Senninger, N.; Weber, T.; Rondot, S.; Hoppner, W.; Raue, F. Long-term outcome in 46 gene carriers of hereditary medullary thyroid carcinoma after prophylactic thyroidectomy: impact of individual RET genotype. Eur. J. Endocrinol. 2006, 155, 229-236.

35. Machens, A.; Gimm, O.; Hinze, R.; Hoppner, W.; Boehm, B.O.; Dralle, H. Genotype-phenotype correlations in hereditary medullary thyroid carcinoma: oncological features and biochemical properties. J. Clin. Endocrinol. Metab. 2001, 86, 1104-1109.

36. Punales, M.K.; Graf, H.; Gross, J.L.; Maia, A.L. RET codon 634 mutations in multiple endocrine neoplasia type 2: variable clinical features and clinical outcome. J. Clin. Endocrinol. Metab. 2003, 88, 2644-2649.

37. Donis-Keller, H. The RET proto-oncogene and cancer. J. Intern. Med. 1995, 238, 319-325.

38. Frank-Raue, K.; Hoppner, W.; Frilling, A.; Kotzerke, J.; Dralle, H.; Haase, R.; Mann, K.; Seif, F.; Kirchner, R.; Rendl, J.; et al. Mutations of the RET protooncogene in German multiple endocrine neoplasia families: relation between genotype and phenotype. German Medullary Thyroid Carcinoma Study Group. J. Clin. Endocrinol. Metab. 1996, 81, 1780-1783.

39. Verga, U.; Fugazzola, L.; Cambiaghi, S.; Pritelli, C.; Alessi, E.; Cortelazzi, D.; Gangi, E.; Beck-Peccoz, P. Frequent association between MEN 2A and cutaneous lichen amyloidosis. Clin. Endocrinol. (Oxf) 2003, 59, 156-161. 
40. Milos, I.N.; Frank-Raue, K.; Wohllk, N.; Maia, A.L.; Pusiol, E.; Patocs, A.; Robledo, M.; Biarnes, J.; Barontini, M.; Links, T.P.; et al. Age-related neoplastic risk profiles and penetrance estimations in multiple endocrine neoplasia type 2A caused by germ line RET Cys634Trp (TGC>TGG) mutation. Endocr. Relat. Cancer 2008, 15, 1035-1041.

41. Frank-Raue, K.; Rybicki, L.A.; Erlic, Z.; Schweizer, H.; Winter, A.; Milos, I.; Toledo, S.P.; Toledo, R.A.; Tavares, M.R.; Alevizaki, M.; et al. Risk profiles and penetrance estimations in multiple endocrine neoplasia type $2 \mathrm{~A}$ caused by germline RET mutations located in exon 10. Hum. Mutat. 2011, 32, 51-58.

42. Gimm, O.; Marsh, D.J.; Andrew, S.D.; Frilling, A.; Dahia, P.L.; Mulligan, L.M.; Zajac, J.D.; Robinson, B.G.; Eng, C. Germline dinucleotide mutation in codon 883 of the RET proto-oncogene in multiple endocrine neoplasia type 2B without codon 918 mutation. J. Clin. Endocrinol. Metab. 1997, 82, 3902-3904.

43. Smith, D.P.; Houghton, C.; Ponder, B.A. Germline mutation of RET codon 883 in two cases of de novo MEN 2B. Oncogene 1997, 15, 1213-1217.

44. Menko, F.H.; van der Luijt, R.B.; de Valk, I.A.; Toorians, A.W.; Sepers, J.M.; van Diest, P.J.; Lips, C.J. Atypical MEN type 2B associated with two germline RET mutations on the same allele not involving codon 918. J. Clin. Endocrinol. Metab. 2002, 87, 393-397.

45. Miyauchi, A.; Futami, H.; Hai, N.; Yokozawa, T.; Kuma, K.; Aoki, N.; Kosugi, S.; Sugano, K.; Yamaguchi, K. Two germline missense mutations at codons 804 and 806 of the RET proto-oncogene in the same allele in a patient with multiple endocrine neoplasia type $2 \mathrm{~B}$ without codon 918 mutation. Jpn. J. Cancer Res. 1999, 90, 1-5.

46. Zedenius, J.; Larsson, C.; Bergholm, U.; Bovee, J.; Svensson, A.; Hallengren, B.; Grimelius, L.; Backdahl, M.; Weber, G.; Wallin, G. Mutations of codon 918 in the RET proto-oncogene correlate to poor prognosis in sporadic medullary thyroid carcinomas. J. Clin. Endocrinol. Metab. 1995, 80, 3088-3090.

47. Hofstra, R.M.; Fattoruso, O.; Quadro, L.; Wu, Y.; Libroia, A.; Verga, U.; Colantuoni, V.; Buys, C.H. A novel point mutation in the intracellular domain of the RET protooncogene in a family with medullary thyroid carcinoma. J. Clin. Endocrinol. Metab. 1997, 82, 4176-4178.

48. Bolino, A.; Schuffenecker, I.; Luo, Y.; Seri, M.; Silengo, M.; Tocco, T.; Chabrier, G.; Houdent, C.; Murat, A.; Schlumberger, M.; et al. RET mutations in exons 13 and 14 of FMTC patients. Oncogene 1995, 10, 2415-2419.

49. Dabir, T.; Hunter, S.J.; Russell, C.F.; McCall, D.; Morrison, P.J. The RET mutation E768D confers a late-onset familial medullary thyroid carcinoma-only phenotype with incomplete penetrance: implications for screening and management of carrier status. Fam. Cancer 2006, 5, 201-204.

50. Eng, C.; Smith, D.P.; Mulligan, L.M.; Healey, C.S.; Zvelebil, M.J.; Stonehouse, T.J.; Ponder, M.A.; Jackson, C.E.; Waterfield, M.D.; Ponder, B.A. A novel point mutation in the tyrosine kinase domain of the RET proto-oncogene in sporadic medullary thyroid carcinoma and in a family with FMTC. Oncogene 1995, 10, 509-513.

51. Kloos, R.T.; Eng, C.; Evans, D.B.; Francis, G.L.; Gagel, R.F.; Gharib, H.; Moley, J.F.; Pacini, F.; Ringel, M.D.; Schlumberger, M.; et al. Medullary thyroid cancer: management guidelines of the American Thyroid Association. Thyroid 2009, 19, 565-612. 
52. Heshmati, H.M.; Gharib, H.; van Heerden, J.A.; Sizemore, G.W. Advances and controversies in the diagnosis and management of medullary thyroid carcinoma. Am. J. Med. 1997, 103, 60-69.

53. Elisei, R.; Cosci, B.; Romei, C.; Bottici, V.; Renzini, G.; Molinaro, E.; Agate, L.; Vivaldi, A.; Faviana, P.; Basolo, F.; et al. Prognostic significance of somatic RET oncogene mutations in sporadic medullary thyroid cancer: a 10-year follow-up study. J. Clin. Endocrinol. Metab. 2008, 93, 682-687.

54. Moura, M.M.; Cavaco, B.M.; Pinto, A.E.; Domingues, R.; Santos, J.R.; Cid, M.O.; Bugalho, M.J.; Leite, V. Correlation of RET somatic mutations with clinicopathological features in sporadic medullary thyroid carcinomas. Br. J. Cancer 2009, 100, 1777-1783.

55. Beldjord, C.; Desclaux-Arramond, F.; Raffin-Sanson, M.; Corvol, J.C.; De Keyzer, Y.; Luton, J.P.; Plouin, P.F.; Bertagna, X. The RET protooncogene in sporadic pheochromocytomas: Frequent MEN 2-like mutations and new molecular defects. J. Clin. Endocrinol. Metab. 1995, 80, 2063-2068.

56. van der Harst, E.; de Krijger, R.R.; Bruining, H.A.; Lamberts, S.W.; Bonjer, H.J.; Dinjes, W.N.; Proye, C.; Koper, J.W.; Bosman, F.T.; Roth, J.; et al. Prognostic value of RET proto-oncogene point mutations in malignant and benign, sporadic phaeochromocytomas. Int. J. Cancer 1998, 79, 537-540.

57. Robledo, M.; Gil, L.; Pollan, M.; Cebrian, A.; Ruiz, S.; Azanedo, M.; Benitez, J.; Menarguez, J.; Rojas, J.M. Polymorphisms G691S/S904S of RET as genetic modifiers of MEN 2A. Cancer Res. 2003, 63, 1814-1817.

58. Wiench, M.; Wygoda, Z.; Gubala, E.; Wloch, J.; Lisowska, K.; Krassowski, J.; Scieglinska, D.; Fiszer-Kierzkowska, A.; Lange, D.; Kula, D.; et al. Estimation of risk of inherited medullary thyroid carcinoma in apparent sporadic patients. J. Clin. Oncol. 2001, 19, 1374-1380.

59. Eng, C.; Mulligan, L.M.; Smith, D.P.; Healey, C.S.; Frilling, A.; Raue, F.; Neumann, H.P.; Pfragner, R.; Behmel, A.; Lorenzo, M.J.; et al. Mutation of the RET protooncogene in sporadic medullary thyroid carcinoma. Genes Chromosom. Cancer 1995, 12, 209-212.

60. Gimm, O.; Neuberg, D.S.; Marsh, D.J.; Dahia, P.L.; Hoang-Vu, C.; Raue, F.; Hinze, R.; Dralle, H.; Eng, C. Over-representation of a germline RET sequence variant in patients with sporadic medullary thyroid carcinoma and somatic RET codon 918 mutation. Oncogene 1999, 18, 1369-1373.

61. Elisei, R.; Cosci, B.; Romei, C.; Bottici, V.; Sculli, M.; Lari, R.; Barale, R.; Pacini, F.; Pinchera, A. $R E T$ exon 11 (G691S) polymorphism is significantly more frequent in sporadic medullary thyroid carcinoma than in the general population. J. Clin. Endocrinol. Metab. 2004, 89, 3579-3584.

62. Rocha, A.P.; Magalhães, P.R.; Maia, A.L.; Maciel, L.Z. Polimorfismos Genéticos: Implicações na Patogênese do Carcinoma Medular de Tireóide. Arq. Bras. Endocrinol. Metab. 2007, 5, 723-730.

63. Cebrian, A.; Lesueur, F.; Martin, S.; Leyland, J.; Ahmed, S.; Luccarini, C.; Smith, P.L.; Luben, R.; Whittaker, J.; et al. Polymorphisms in the initiators of RET (rearranged during transfection) signaling pathway and susceptibility to sporadic medullary thyroid carcinoma. J. Clin. Endocrinol. Metab. 2005, 90, 6268-6274.

64. Fugazzola, L.; Muzza, M.; Mian, C.; Cordella, D.; Barollo, S.; Alberti, L.; Cirello, V.; Dazzi, D.; Girelli, M.E.; Opocher, G.; et al. RET genotypes in sporadic medullary thyroid cancer: Studies in a large Italian series. Clin. Endocrinol. (Oxf) 2008, 69, 418-425. 
65. Lesueur, F.; Cebrian, A.; Robledo, M.; Niccoli-Sire, P.; Svensson, K.A.; Pinson, S.; Leyland, J.; Whittaker, J.; Pharoah, P.D.; Ponder, B.A. Polymorphisms in RET and its coreceptors and ligands as genetic modifiers of multiple endocrine neoplasia type 2A. Cancer Res. 2006, 66, 1177-1180.

66. Baumgartner-Parzer, S.M.; Lang, R.; Wagner, L.; Heinze, G.; Niederle, B.; Kaserer, K.; Waldhausl, W.; Vierhapper, H. Polymorphisms in exon 13 and intron 14 of the RET protooncogene: Genetic modifiers of medullary thyroid carcinoma? J. Clin. Endocrinol. Metab. 2005, 90, 6232-6236.

67. Sharma, B.P.; Saranath, D. RET gene mutations and polymorphisms in medullary thyroid carcinomas in Indian patients. J. Biosci. 2011, 36, 603-611.

68. Sromek, M.; Czetwertynska, M.; Skasko, E.; Zielinska, J.; Czapczak, D.; Steffen, J. The frequency of selected polymorphic variants of the RET gene in patients with medullary thyroid carcinoma and in the general population of central Poland. Endocr. Pathol. 2010, 21, 178-185.

69. Wohllk, N.; Soto, E.; Bravo, M.; Becker, P. Polimorfismos G691S, L769L y S836S del proto-oncogen RET no se asocian a mayor riesgo de cáncer medular tiroideo esporádico en pacientes chilenos. Rev. Méd. Chile 2005, 133, 397-402.

70. Magalhães, P.K.; de Castro, M.; Elias, L.L.; Soares, E.G.; Maciel, L.M. Polymorphisms in the $R E T$ proto-oncogene and the phenotypic presentation of familial medullary thyroid carcinoma. Thyroid 2004, 14, 848-852.

71. Berard, I.; Kraimps, J.L.; Savagner, F.; Murat, A.; Renaudin, K.; Nicolli-Sire, P.; Bertrand, G.; Moisan, J.P.; Bezieau, S. Germline-sequence variants S836S and L769L in the RE arranged during Transfection (RET) proto-oncogene are not associated with predisposition to sporadic medullary carcinoma in the French population. Clin. Genet. 2004, 65, 150-152.

72. Ruiz, A.; Antinolo, G.; Fernandez, R.M.; Eng, C.; Marcos, I.; Borrego, S. Germline sequence variant $\mathrm{S} 836 \mathrm{~S}$ in the RET proto-oncogene is associated with low level predisposition to sporadic medullary thyroid carcinoma in the Spanish population. Clin. Endocrinol. (Oxf) 2001, 55, 399-402.

73. Tamanaha, R.; Camacho, C.P.; Pereira, A.C.; da Silva, A.M.; Maciel, R.M.; Cerutti, J.M. Evaluation of RET polymorphisms in a six-generation family with G533C RET mutation: specific RET variants may modulate age at onset and clinical presentation. Clin. Endocrinol. (Oxf) 2009, $71,56-64$.

74. Griseri, P.; Sancandi, M.; Patrone, G.; Bocciardi, R.; Hofstra, R.; Ravazzolo, R.; Devoto, M.; Romeo, G.; Ceccherini, I. A single-nucleotide polymorphic variant of the RET proto-oncogene is underrepresented in sporadic Hirschsprung disease. Eur. J. Hum. Genet. 2000, 8, 721-724.

75. Borrego, S.; Wright, F.A.; Fernandez, R.M.; Williams, N.; Lopez-Alonso, M.; Davuluri, R.; Antinolo, G.; Eng, C. A founding locus within the RET proto-oncogene may account for a large proportion of apparently sporadic Hirschsprung disease and a subset of cases of sporadic medullary thyroid carcinoma. Am. J. Hum. Genet. 2003, 72, 88-100.

76. Lu, H.; Huan, C. Transcription factor NFAT, its role in cancer development, and as a potential target for chemoprevention. Curr. Cancer Drug Targets 2007, 7, 343-353.

(C) 2012 by the authors; licensee MDPI, Basel, Switzerland. This article is an open access article distributed under the terms and conditions of the Creative Commons Attribution license (http://creativecommons.org/licenses/by/3.0/). 